\title{
Desenvolvimento de formulações e tecnologia de obtenção de comprimidos revestidos de efavirenz - terapia anti-HIV
}

\author{
Osnir de Sá Viana1, José Benigno Júnior ${ }^{1}$, Rosali Maria Ferreira Silva², Flávia Patrícia Morais de \\ Medeiros $^{2}$, Severino Grangeiro Júnior ${ }^{2}$, Miracy Muniz de Albuquerque ${ }^{1}$, Pedro José Rolim Neto*1,2 \\ ${ }^{1}$ Departamento de Ciências Farmacêuticas, Universidade Federal de Pernambuco, ${ }^{2}$ Laboratório Farmacêutico \\ do Estado de Pernambuco - LAFEPE
}

*Correspondência:

P. J. Rolim Neto

Laboratório de Tecnologia de

Medicamentos (LTM)

Departamento de Ciências Farmacêuticas

Rua Arthur de Sá, S/N

50740-521 Recife - PE, Brasil

E-mail: pedro.rolim@pq.cnpq.br
O efavirenz é uma das mais recentes classes de agentes antiretrovirais aplicados no tratamento de infecções por HIV. Está entre os medicamentos de primeira escolha no tratamento da AIDS. Como o efavirenz possui característica hidrofóbica, baixa densidade e oferece grande resistência ao escoamento, a escolha de uma formulação adequada deste fármaco é essencial no desenvolvimento dos comprimidos e para garantir melhor disponibilização no trato gastrointestinal, de forma a alcançar a biodisponibilidade e o efeito terapêutico desejados. Neste trabalho, apresentamos, de forma lógica, o desenvolvimento tecnológico de comprimidos revestidos de efavirenz, levando em consideração suas características físicas e físico-químicas. Os núcleos (comprimidos) de efavirenz foram obtidos utilizando-se a técnica de granulação por via úmida. No revestimento por película utilizou-se Opadry ${ }^{\circledR}$ Y-1-7000 em sistema aquoso. Os parâmetros adotados para avaliação física dos comprimidos seguiram as especificações farmacopéicas oficiais e a determinação quantitativa foi realizada mediante método analitico desenvolvido e validado.
Unitermos

- Efavirenz

- Anti-retroviral

- Comprimidos revestidos

- Desenvolvimento tecnológico

\section{INTRODUÇÃO}

A via oral é, sem dúvida, a mais utilizada na administração de medicamentos. Embora seja a mais aceita pelos pacientes, nem sempre é a mais adequada à administração de fármacos, já que fármacos pouco solúveis ou incluídos em formas farmacêuticas mal elaboradas podem não ser completamente absorvidos. Em circunstâncias normais, pode-se esperar que o fármaco permaneça no estômago por 2 a 4 horas (tempo de esvaziamento gástrico) e no intestino delgado durante 4 a 10 horas. Desta forma, no desenvolvimento de uma nova formulação, deve-se dar atenção a fatores capazes de retardar ou acelerar o processo de disponibilização do fármaco no trato gastrointestinal, dentre os quais os relacionados com a formulação: tamanho da partícula, tempo de desintegração, dissolução, presença de excipientes hidrofóbicos e/ou hidrofílicos, propri- 
edades físico-químicas e outras características do fármaco (Longer, Robinson, 1995).

O revestimento por película é um processo que envolve a deposição de uma película fina e uniforme na superfície do substrato, podendo ser utilizado com o objetivo de mascarar odor e sabor da substância, ou de proteção para princípios ativos pouco estáveis (Stuart, 2004).

Os principais componentes para qualquer formulação de revestimento por película constituem em polímeros, plastificante, corante e solventes. As propriedades ideais para o polímero incluem solubilidade em ampla gama de sistemas solventes, habilidade em produzir revestimentos que possuam propriedades mecânicas adequadas e solubilidade apropriada nos líquidos gastrointestinais, de modo que a biodisponibilidade não seja comprometida. Éteres de celulose são freqüentemente os polímeros preferidos no revestimento por película, sobretudo hidroxipropilmetilcelulose. Substitutos adequados são a hidroxipropilcelulose, que pode produzir revestimentos levemente mais aderidos. Alternativas aos éteres de celulose são certos acrílicos, como os co-polímeros metacrilato e metacrilato de metila (Stuart, 2004).

O efavirenz é um anti-retroviral não-análogo de nucleosídeo inibidor não competitivo da transcriptase reversa do vírus HIV. Liga-se diretamente a esta enzima e bloqueia as atividades da DNA-polimerase RNA e DNA-dependentes, causando a destruição do sítio catalítico da enzima. O efavirenz (Figura 1) possui forma molecular $\mathrm{C}_{14} \mathrm{H}_{9} \mathrm{ClF}_{3} \mathrm{NO}_{2}$, é opticamente ativo e com massa molecular de 315,68 . Possui aparência de pó cristalino branco ou levemente amarelado (Figura 2) e apresenta faixa de fusão de $136,0^{\circ} \mathrm{C}-141,0{ }^{\circ} \mathrm{C}$, é praticamente insolúvel em água, mas solúvel em metanol e diclorometano (Clercq, 2001).

O objetivo deste trabalho foi o estudo das propriedades de fluxo do efavirenz e a tecnologia de obtenção de comprimidos revestidos à base deste fármaco.

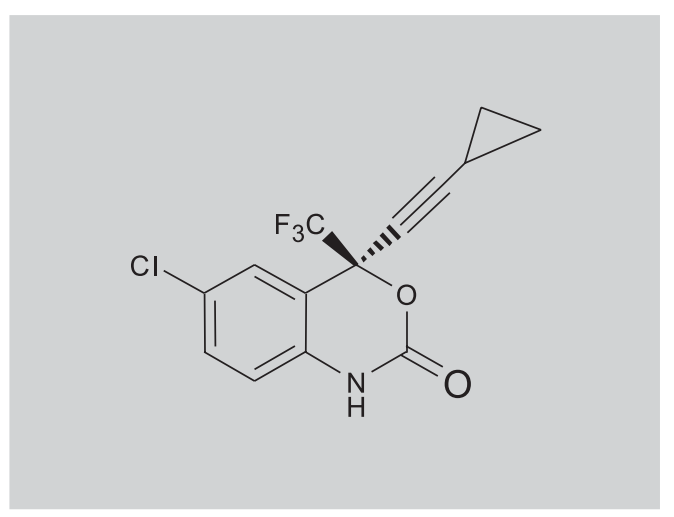

FIGURA 1 - Estrutura química do efavirenz.

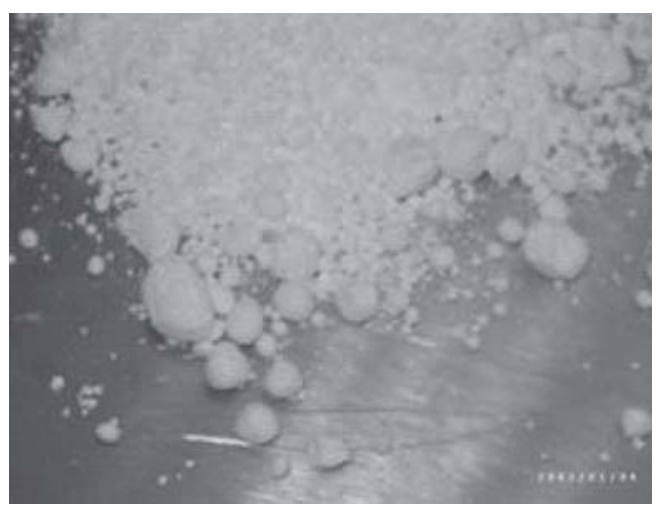

FIGURA 2 - Características macroscópicas do pó (branco ou levemente amarelado, as vezes em forma floculada).

\section{MATERIAL E MÉTODOS}

\section{Estudo das propriedades de fluxo do efavirenz matéria- prima e escolha da técnica para obtenção dos comprimidos}

Ângulo de repouso e velocidade de escoamento do efavirenz (matéria-prima e granulado)

$\mathrm{O}$ ângulo de repouso foi determinado de acordo com o método de altura fixa do funil e cone de base variável. Deixou-se cair uma quantidade padronizada de pó/granulado (30 g), o mais regularmente possível, em um funil de $8,3 \mathrm{~cm}$ de diâmetro superior e $0,7 \mathrm{~cm}$ de diâmetro inferior, até formar um cone. O diâmetro (2R) do cone formado foi medido. A tangente do ângulo de repouso foi dada por tg $D=H / R$, onde Dé o ângulo de repouso, $H$ altura e $\mathrm{R}$ o raio do cone. Foi calculado o valor médio de 3 determinações. $\mathrm{O}$ tempo de escoamento foi medido em segundos (Prescott, Barnum, 2000).

\section{Densidade compactada do efavirenz}

$\mathrm{O}$ teste de densidade aparente e compactada do efavirenz foi realizado utilizando-se um aparato dotado de proveta de $150 \mathrm{~mL}$, fixada em um compactador automático. O equipamento promoveu a compactação do pó em movimentos verticais padronizados. O volume do efavirenz (lote EF 0140503) ocupado na proveta foi medido. As compactações variaram de 1-1250 vezes. Utilizou-se quantidade de 50 gramas de efavirenz. A média foi obtida a partir de três determinações (Monteiro, 2000).

\section{Desenvolvimento de comprimidos revestidos de efavirenz}

\section{Materiais}

Levando-se em consideração as características físicas e físico-químicas do pó de efavirenz, realizou-se pla- 
nificação qualitativa e quantitativa de excipientes. As matérias-primas com seus respectivos fabricantes foram: efavirenz (Fabricante Hetero Labs ${ }^{\circledR}$ ); lauril sulfato de sódio $\left(\right.$ Nuclear $\left.^{\circledR}\right)$; hidroxipropilcelulose $\left(\right.$ Denver $\left.^{\circledR}\right)$; celulose microcristalina 250 e $101\left(\right.$ Blanver $\left.^{\circledR}\right)$; polivinilpirrolidona $\left(\mathrm{Xiamem}^{\circledR}\right)$; crospovidona (ISP Technologies ${ }^{\circledR}$ ); croscarmelose (Rellance celulose ${ }^{\circledR}$ ); Estearato de Magnésio $\left(\right.$ Blanver $\left.^{\circledR}\right)$; dióxido de silício coloidal $\left(\right.$ Henkel $\left.^{\circledR}\right)$. Os equipamentos utilizados no processo de obtenção dos comprimidos revestidos foram: misturador em "V" (Lawes $\left.{ }^{\circledR}\right)$; granulador oscilante (Fabbe-Primar $\left.{ }^{\circledR}\right)$; estufa industrial $\left(\right.$ Imarvil $\left.^{\circledR}\right)$; compressora rotativa com 16 punções $\left(\right.$ Newberger $\left.^{\mathbb{R}}\right)$ e drageadeira convencional.

Baseando-se em planificação qualitativa e quantitativa de excipientes, foram manipulados oito lotes de bancada (LB) contendo $300 \mathrm{~g}$ de massa de pós, os quais estão descritos na Tabela I. Os lotes de bancada de I ao III foram calculados para obtenção de comprimidos com peso médio de $950 \mathrm{mg}$ e os lotes de bancada de IV ao VIII foram formulados para obtenção de comprimidos com $850 \mathrm{mg}$ de peso médio.

\section{Técnica de Obtenção dos comprimidos}

No intuito de melhorar as propriedades de fluxo do efavirenz, requisito necessário para alcançar escoamento adequado durante a alimentação da máquina compressora e no enchimento das matrizes de compressão (Prescott,
Barnum, 2000), foi discutido e decidido pela equipe de desenvolvimento, que todos os lotes de bancada seriam obtidos utilizando-se a técnica de granulação por via úmida (Monteiro, 2000).

Produziu-se um granulado do princípio ativo (efavirenz) - ETAPA 1. A mistura de pós foi levemente umedecida com a solução aglutinante até obter massa coesiva. Após passagem pelo granulador oscilante, a massa foi submetida à secagem em estufa industrial (50 ${ }^{\circ} \mathrm{C}$ por 3 horas).

Na ETAPA II, o granulado seco foi calibrado (tamisado) em malha de 1,5 mm, misturado com os demais excipientes e submetido à compressão. Foram utilizados punções circulares côncavos de $13 \mathrm{~mm}$, na obtenção dos lotes de bancada de I a IV. Nos lotes de bancada de V a VIII foram utilizados punções oblongos de $17 \mathrm{~mm}$, de forma a obter maior distribuição da massa no comprimido, reduzindo o volume deste e facilitando a adesão do paciente ao tratamento.

Em todas as formulações contendo hidroxipropilcelulose (HPC), como agente agregante, este foi dividido em duas partes, uma para ser adicionada na mistura de pós e a outra parte, na solução aglutinante.

Os núcleos (comprimidos) obtidos foram submetidos aos testes físico-químicos: peso médio, uniformidade de peso, dureza, friabilidade e desintegração (Farmacopéia Brasileira IV, 1988). O método de dissolução do efavirenz utilizou o equipamento de dissolução Wankel VK 7010, aparatos II (pá), rotação de 75 rpm, meio de dissolução

TABELA I - Lotes de bancada desenvolvidos

\begin{tabular}{|c|c|c|c|c|c|c|c|c|c|c|}
\hline & COMPONENTE & $\mathrm{LBI} \%$ & LB II\% & LB III $\%$ & LB IV\% & LBV\% & LB VI\% & LBVII $\%$ & LBVIII\% & FUNÇÃO \\
\hline \multirow[t]{10}{*}{ ETAPAI } & Efavirenz & 63,16 & 63,16 & 63,16 & 70,59 & 70,59 & 70,59 & 70,59 & 70,59 & Princípio ativo \\
\hline & Hidroxipropilcelulose & 0,32 & 1,05 & 1,05 & 1,05 & 1,05 & 1,05 & - & - & Agregante \\
\hline & Lauril sulfato de sódio & 1,05 & 1,05 & 1,05 & 1,05 & 1,05 & 1,05 & 1,05 & 1,05 & Tensoativo \\
\hline & Croscarmelose sódica & 1,05 & 1,05 & - & - & - & - & - & 1,15 & Desintegrante \\
\hline & Hidroxipropilcelulose & & & & & & & & & \\
\hline & (KLUCEL) em sol. & 1,05 & 0,32 & 0,32 & 0,32 & 0,32 & 0,32 & - & - & Ligante \\
\hline & Polivinilpirrolidona & - & - & - & - & - & - & 1,37 & 1,37 & Ligante \\
\hline & Celulose Microcristalina & & & & & & & & & \\
\hline & 101 & - & - & - & - & - & 19,94 & 19,94 & 19,94 & Diluente \\
\hline & Água desionizada & q.s. & q.s. & q.s. & q.s. & q.s & q.s & q.s & q.s & Solução molhante \\
\hline \multirow[t]{6}{*}{ ETAPA II } & Celulose microcristalina & & & & & & & & & \\
\hline & 250 & 27,37 & 27,37 & 27,37 & 19,94 & 19,94 & - & - & - & Diluente \\
\hline & Estearato de magnésio & 1,58 & 1,58 & 1,58 & 1,58 & 1,58 & 1,58 & 1,58 & 1,58 & Lubrificante \\
\hline & Aerosil & 1,26 & 1,26 & 1,26 & 1,26 & 1,26 & 1,26 & 1,26 & 1,26 & Desumidificante \\
\hline & Croscarmelose sódica & 1,26 & 1,26 & 2,31 & 2,31 & 2,31 & 2,31 & 2,31 & 1,16 & Desintegrante \\
\hline & Crospovidona & 1,90 & 1,90 & 1,90 & 1,90 & 1,90 & 1,90 & 1,90 & 1,90 & Desintegrante \\
\hline TOTAL & & 100 & 100 & 100 & 100 & 100 & 100 & 100 & 100 & \\
\hline
\end{tabular}


composto por lauril sulfato de sódio $1 \%$, temperatura de $37^{\circ} \mathrm{C}( \pm 0,5)$. A solução padrão utilizada na dissolução foi de $12 \mathrm{Pg} / \mathrm{mL}$ de efavirenz no meio de dissolução e as leituras das absorbâncias das soluções amostra e padrão foram obtidas em especrofotômetro Shimadzu UV 2401PC, em comprimento de onda de $247 \mathrm{~nm}$. O teor dos comprimidos foi avaliado por cromatografia líquida de alta eficiência, método previamente validado. A superfície dos comprimidos foi avaliada a partir de fotografia com resolução de 8 milhões de pixels e zoom óptico de 4 x, utilizando máquina Sony Cyber-shot DSC-F828 ${ }^{\circledR}$.

Para o revestimento por película desenvolvido utilizou-se o Opadry Y-1-7000 como polímero disperso em sistema aquoso. O Lote de Bancada submetido aos testes de revestimento foi o LB VIII. Todos os parâmetros definidos para o processo de revestimento foram controlados: temperatura de secagem $\left(35 \pm 2{ }^{\circ} \mathrm{C}\right)$, rotação da drageadeira (20 rpm), distância da pistola de aspersão para o leito dos comprimidos $(20 \mathrm{~cm})$, pressão da bomba de pulverização (3 Bar). A eficiência do revestimento foi avaliada pelas características macroscópicas e pelo ganho de peso alcançado após o processo.

Os comprimidos revestidos obtidos foram submetidos a testes comparativos com o medicamento de referência, o Stocrin ${ }^{\circledR}$ do laboratório Merck Sharp \& Dohme.

\section{RESULTADOS E DISCUSSÃO}

Os resultados do estudo das propriedades de fluxo, dos pós de efavirenz (matéria-prima e granulado), estão demonstrados no Quadro I. Como se pode observar, houve melhora destas propriedades após granulação do princípio ativo.

A densidade aparente e compactada do efavirenz matéria-prima foi respectivamente 0,389 e $0,397 \mathrm{~g} / \mathrm{mL}$, confirmando a baixa densidade deste fármaco. Esse fator, associado à elevada resistência ao escoamento, tornou inviável a tentativa de formulação para compressão por via direta. Além disso, a característica de aderência em superfícies de diversos materiais (plástico, metais, entre outros) tornou a granulação por via úmida, o pro- cesso escolhido para melhorar as propriedades de fluxo do efavirenz.

Durante o processo de granulação por via úmida, a etapa de malaxagem (molhagem da mistura de pós) apresentou-se como a mais crítica no processo de obtenção dos comprimidos de efavirenz. Diferentemente da maioria das granulações por via úmida, nesta a mistura de pós foi levemente umedecida. Durante o processo de desenvolvimento dos comprimidos houve várias perdas de massa, devido ao limite de agente molhante ter excedido à quantidade máxima admitida, que foi de aproximadamente $60 \mathrm{~mL}$ para $300 \mathrm{~g}$ de pós, verificada após vários testes. Ao exceder esse limite, a massa tomava rapidamente aspecto de resina, bastante pegajosa. A verificação e a definição da etapa molhagem possibilitaram a obtenção de um granulado mais adequado para produção dos comprimidos.

Em razão dos resultados obtidos no LB I e LB II (Tabela II), optou-se por retirar da fase interna a croscamelose (Tabela I), utilizada como super desintegrante e adicionar ao percentual já existente na fase externa. Desta forma, tempo menor de desintegração foi alcançado no LB III. Como essa formulação estava resultando em núcleos com dimensões elevadas ( $8,5 \mathrm{~mm}$ de espessura), o que dificultaria a administração da forma farmacêutica ao paciente, e considerando que este paciente utiliza diferentes esquemas terapêuticos, foi decidido trabalhar o peso médio, sendo este reduzido para $850 \mathrm{mg}$ no LB IV. Porém, sua redução ocorreu como de rotina no diluente (celulose microcristalina 250). Houve melhora nas dimensões dos núcleos, entretanto, ainda apresentavam volume elevado. Decidiu-se, então, efetuar mudança de ferramental para obtenção do núcleo, sendo realizado mais um lote de bancada. No LB V foi reproduzida a mesma formulação do LB IV, porém utilizando punções oblongos de $17 \mathrm{~mm}$ de comprimento. Esta alteração proporcionou melhor distribuição do pó (devido ao formato cilíndrico) e dimensões mais adequadas (Figura 3), uma vez que no caso de revestimento por película, a altura dos comprimidos e o raio de curvatura influem na quantidade do material a ser incorporado. Quanto mais espesso for o comprimido, mais frágil e lento será o revestimento.

QUADRO I - Tempo de escoamento e ângulo de repouso da matéria-prima e dos granulados de efavirenz

\begin{tabular}{|c|c|c|c|c|c|c|c|c|}
\hline \multirow{2}{*}{\multicolumn{2}{|c|}{ Especificação }} & \multirow{2}{*}{$\begin{array}{c}\text { Efavirenz } \\
\text { matéria-prima }\end{array}$} & \multicolumn{6}{|c|}{ GRANULADO } \\
\hline & & & LB I & LBII & LB III & LB IV & LBVII & LBVIII \\
\hline $\begin{array}{l}\text { Tempo de } \\
\text { escoamento (s) } \\
\text { Ângulo de }\end{array}$ & - & Infinito & 4,6 & 4,2 & 3,8 & 6,5 & 3,4 & $3,0 \mathrm{~s}$ \\
\hline repouso $\left(^{\circ}\right)$ & $<30$ & - & 28,2 & 26,6 & 25,6 & 37,0 & 24,3 & 22,4 \\
\hline
\end{tabular}




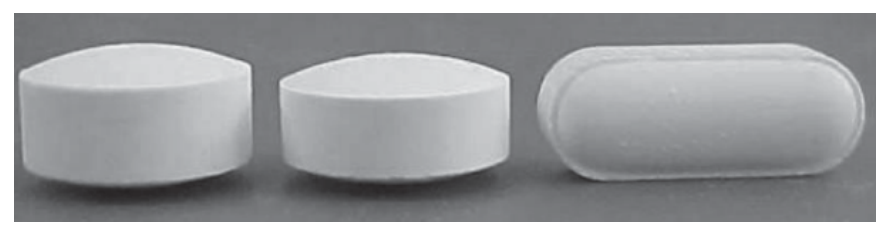

FIGURA 3 - Comprimidos de efavirenz desenvolvidos (LB III, LB IV e LBVIII).

Apesar de se ter resolvido o problema de dimensões do núcleo, observou-se que o uso da celulose microcristalina 250 na etapa II, como excipiente de compressão direta e com características de pó fino, misturado ao granulado do princípio ativo, estava resultando em uma diferença na densidade dos pós, com distribuição heterogenea nas matrizes, dificultando a obtenção do peso médio determinado. A obtenção deste peso médio só foi possível com a máquina compressora operando no seu limite máximo de pressão, o que não é interessante em uma rotina industrial, comprometendo a vida útil do equipamento.

Decidiu-se, então, realizar uma planificação qualitativa entre os diluentes, retirando a celulose 250 da fase externa e substituindo pela celulose microcristalina 101 adicionada na fase interna, uma vez que este último excipiente é um dos mais adequados para via úmida. Houve melhora significativa no processo, com uniformidade na distribuição dos grânulos na câmara de enchimento e conseqüente uniformidade de peso, e nos parâmetros de dureza e desintegração.

Na avaliação de superfície dos comprimidos, observou-se que aqueles nos quais se utilizou HPC como agente agregante apresentaram superfície com grande presença de rugosidades (Figura 4), o que prejudicaria a adesividade do polímero durante o revestimento. Esta rugosidade foi atribuída ao ligante hidroxipropilcelulose. Este, no LB VII, foi substituído pela polivinilpirrolidona (PVP), adicionada à solução molhante. Desta forma, os comprimidos obtidos nos lotes de bancada VII e VIII apresentaram-se com

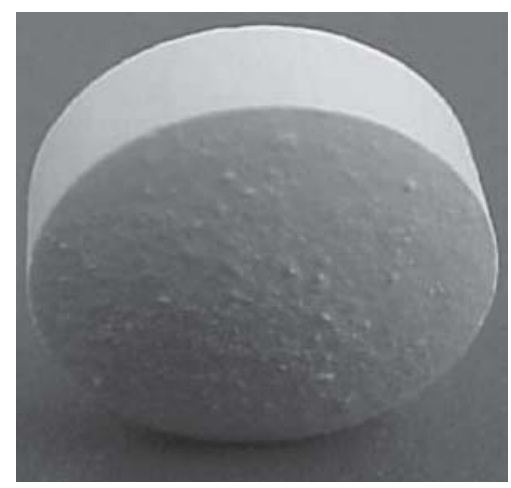

FIGURA 4 - LB III - Presença de rugosidades. superfície mais homogênea, aspecto mais liso e uniforme, sem rebarbas ou superfícies irregulares (Figura 5), o que facilita a obtenção de revestimento bem definido. No LB VIII, percentual da croscarmelose foi transferido da fase externa para a fase interna pra melhorar o processo de desagregação dos grânulos obtidos na etapa I.

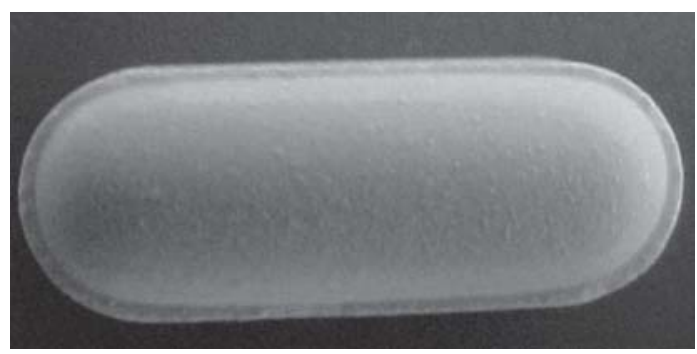

FIGURA 5 - LB VIII - Comprimido bem definido, com superfície homogênea.

$\mathrm{Na}$ avaliação dos núcleos obtidos, submetidos ao processo de revestimento, foram adotados os parâmetros farmacopéicos (peso médio, dureza, friabilidade e desintegração). A dissolução e o teor foram avaliados através de metodologias analíticas previamente validadas. Os resultados estão na Tabela II.

Todos os comprimidos apresentaram-se dentro das especificações farmacopéicas, com exceção do LB VI, que ficou fora das especificações de peso médio e com maior tempo de desintegração.

A elevada dureza observada em alguns lotes de bancada está relacionada, entre outros fatores, à característica de compactação e grande poder de coesão do efavirenz, o que fez com os comprimidos alcançassem durezas maiores de $20,0 \mathrm{kgf} / \mathrm{cm}^{2}$, chegando até a $33,2 \mathrm{kgf} / \mathrm{cm}^{2}$ no LB VI.

Por suas características organolépticas, tornou-se necessária a utilização de um revestimento para mascar odor e sabor do efavirenz nos comprimidos. O lote de bancada VIII foi submetido ao processo de revestimento, por ter apresentado os melhores resultados físico-químicos, superfície mais homogênea e bem definida. O revestimento utilizando sistema aquoso - Opadry Y-1-7000 disperso em água, mostrou-se simples e prático. A deposição do polímero na superfície dos comprimidos foi homogênea e uniforme, sem presença de falhas. O ganho de peso dos comprimidos revestidos, em relação aos núcleos, foi de $2,11 \%$, dentro do recomendado para revestimentos por película é entre $2-3 \%$.

Os resultados comparativos entre os comprimidos teste e os de referência estão apresentados na Tabela III.

Ambos os comprimidos (referência e teste) atendem aos requisitos farmacopéicos avaliados, mesmo diferindo 
TABELA II - Resultados do controle físico-químico dos comprimidos obtidos

\begin{tabular}{|c|c|c|c|c|c|c|c|c|c|}
\hline PARÂMETRO & ESPECIFICAÇÃO & LBI & LB II & LB III & LB IV & LBV & LBVI & LB VII & LB VIII \\
\hline Peso Médio(mg) & $\begin{array}{l}950 \mathrm{mg} \pm 5 \%(\mathrm{LBI}, \\
\text { II, III) } 850 \mathrm{mg} \pm 5 \% \\
\text { (LB IV-VIII) }\end{array}$ & 946,60 & 946,30 & 938,10 & 843,10 & $836,00 *$ & $790,00 * *$ & 846,00 & 827,00 \\
\hline Dureza $\left(\mathrm{kgf} / \mathrm{cm}^{2}\right)$ & $>8,0$ & 26,12 & 17,89 & 14,28 & 18,67 & 22,40 & 33,20 & 16,50 & 14,49 \\
\hline Friabilidade (\%) & $<1,00$ & 0,10 & 0,13 & 0,22 & 0,24 & 0,11 & 0,14 & 0,22 & 0,04 \\
\hline Desintegração (min) & $<30^{\prime}$ & 6 & 3’40”' & $1 ' 36 "$ & 4'35'” & 9’35" & $22^{\prime} 30^{\prime \prime}$ & 5'30”' & 3'45' \\
\hline Dissolução (\%) & $>80 \%$ em $45 \mathrm{~min}$ & 98,43 & 92,31 & 91,42 & 84,86 & 87,30 & 78,20 & 80,40 & 100,20 \\
\hline Teor $(\%)$ & Entre $90-110$ & 96,70 & 98,27 & 99,20 & 101,80 & 102,16 & 94,60 & 98,30 & 102,30 \\
\hline
\end{tabular}

* Não houve uniformidade de peso médio **Não atingiu o peso médio.

TABELA III - Testes comparativos entre os comprimidos revestidos de efavirenz 600 mg: Teste x Referência (Stocrin ${ }^{\circledR}$ - Merck Sharp \& Dohme)

\begin{tabular}{lccc}
\hline PARÂMETRO & ESPECIFICAÇÃO & Referência & Teste \\
& & & LB VIII \\
\hline Peso Médio (mg) & - & 1241,0 & 863,7 \\
Dureza (kgf/cm $\left.{ }^{2}\right)$ & $>8,0$ & 28,10 & 17,45 \\
Desintegração (min) & $<30$ min & 10 ’40” & 1 '40” \\
Dissolução (\%) & $>80 \%$ em 45 min & 99,66 & 88,53 \\
Teor (\%) & Entre 90-110 & 103,56 & 99,20 \\
\hline
\end{tabular}

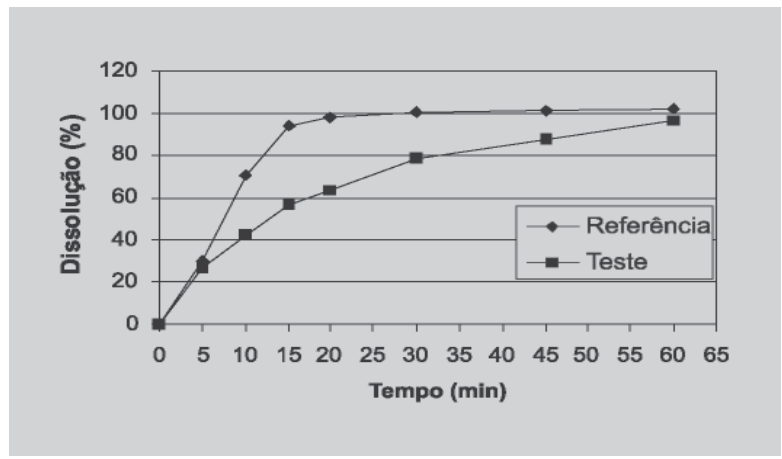

FIGURA 6 - Perfil de liberação comparativo - comprimido teste frente ao de referência.

quanto ao perfil de dissolução (Figura 6). Pode-se observar a liberação superior a $80 \%$ em 45 minutos para os dois produtos estudados. O revestimento do medicamento de referência utiliza um sistema orgânico. Como os núcleos dos comprimidos revestidos desenvolvidos apresentaram dissolução acima de 98\% em 45 minutos, trabalha-se com a hipótese de que o revestimento aquoso possa está interferindo no processo de dissolução do efavirenz. Portanto, deve-se realizar um estudo utilizando revestimentos orgânicos, para avaliação da influência do tipo de sistema utilizado na dispersão do polímero, no processo de dissolução deste fármaco.

\section{CONCLUSÕES}

Todos os comprimidos obtidos das oito formulações testadas apresentaram resultados dentro das especificações farmacopéicas, com exceção do LB VI. Entretanto, os Lotes de bancada do I ao V apresentaram superfície com presença de rugosidades, o que não é adequado para revestimentos por película. O lote de bancada VIII mostrou os melhores resultados, com homogeneidade de conteúdo, peso e superfície bem definida, lisa e uniforme, o que facilitou o processo de revestimento. $\mathrm{O}$ revestimento aquoso vem se demonstrando como uma alternativa em relação aos revestimentos que utilizam solventes orgânicos, como álcool isopropílico, diclorometano, que apresentam toxicidade. O processo utilizando revestimentos aquosos se torna mais simples e rápido, com menor risco da presença de impurezas residuais. Entretanto serão necessários mais estudos para avaliação da influência do tipo de sistema de dispersão utilizado (orgânico ou aquoso) no processo de dissolução do efavirenz. A forma farmacêutica aqui desenvolvida, comprimidos revestidos de efavirenz, representa grande contribuição da rede pública de produção para o Programa DST-AIDS, do Ministério da Saúde-Brasil. 


\section{ABSTRACT}

\section{Development of formulations and technology of efavirenz coated tablets obtention - anti-HIV therapy}

Efavirenz is one of the most recent classes of antiretroviral drugs used in the treatment of HIV infections. It is the first choice therapy for AIDS treatment. As efavirenz detains hydrofobic characteristic, low density and offers great resistance to draining, it has been essential to choose an adequated formulation for it, in order to guarantee drug's availability in gastro-intestinal tract, achieving bioavailability and expected therapeutical effects. This work presents efavirez coated tablets thecnological development, considering the physics and physico-chemical characteristics of this drug. The efavirez nucleus (tablets) has been obtained employing granulation technics by humid via. In the coating by film, Opadry Y-1-7000 in aquous system was used. The adopted parameters to tablet phisics evaluation followed official phamacopeial specifications and quantitative determination of the drug was performed by developed and validated methodology.

UNITERMS: Efavirenz. Anti-retroviral. Coated tablets. Technological development.

\section{REFERÊNCIAS BIBLIOGRÁFICAS}

BAICHWALL, A; NEVILLE, D.A. Culturing innovation and enhancing medication using oral drug delivery. Drug Del. technol. v.2, n. 3, p.65-68, 2002.

BRASIL. Ministério da Saúde. Programa Nacional DST AIDS. Recomendações para terapia anti-retroviral em adultos e adolescentes infectados pelo HIV 2004. Brasília, 2004. 61p.

BRASIL, Resolução - RE n ${ }^{\circ}$ 310, de 01 de Setembro de 2004 - Guia para estudo de equivalência farmacêuticaPerfil de dissolução - Agência Nacional de Vigilância Sanitária, Poder Executivo, Brasilia - DF, D.O.U. de 22 de dezembro de 2000.

CAMPOS, R. Brasil: modelo no combate à AIDS. Industria farmacêutica. Segmento n.4, p. 8-13., 2004.
CLERCQ, E. Antiviral drugs: current state of the art. J. Clin. Vir., v.22, p.73-89, 2001.

FARMACOPÉIA Brasileira. Parte I - Métodos Gerais. 4 ed. São Paulo: Atheneu, 1998. v. 5.1.9.1-3.

HALLAL, R. Tendências da terapia antiretroviral no Brasil. In: 1 ${ }^{\text {a }}$ Oficina de Trabalho da Associação dos Laboratórios Farmacêuticos Oficiais do Brasil-ALFOB. Brasília: 2004.

LACHMAN, L.; LIEBERMAN, H.A; KANIG, J.L. Teoria e prática na indústria farmacêutica. Lisboa: Fundação Calouste Gulbenkian, 2001. vol. 2, p. 509-599.

LONGER, M. A.; ROBINSON, J.R. Sistema de liberação sustentada de drogas In: GENARO, A.R. Remington Farmácia. 17. ed. Buenos Aires: Editorial Panamericana, 1995, v.2.

MONTEIRO, D.B. Tecnologia de obtenção de comprimidos revestidos de lamivudina, transposição de escala, validação da metodologia analítica, estudo de estabilidade e equivalência farmacêutica. Recife, 2000. 146p. [Dissertação de Mestrado em Ciências Farmacêuticas. Universidade Federal de Pernanbuco].

PRESCOTT, J. K.; BARNUM, R.A. Sobre a fluidez de pós. Pharm. Technol., v. 4, n. 6, p 16-30, 2000.

STUART, P. C. Revestimento de formulações farmacêuticas. In: GENNARO, A. R. Remmington: a ciência e a prática farmacêutica. 20 ed. Rio de Janeiro: Guanabara Koogan, 2004. cap. 46, p.923-932.

UNITED STATES PHARMACOPEIA. 28 ed. Rockville: The United Pharmacopeia Conventional, 2004. 3187p.

WANDE, A. N. Handbook of pharmaceutical excipients. 2 ed. Washington: American Pharmaceutical Association, 1994.

LU, W.; ARRAES, L. C.; FERREIRA, W. T. F.; ANDRIEU, J.-M. Therapeutic dendritic-cell vaccine for chronic HIV1 infection. Nature Med., v. 10, n. 12, p.1359-1365, 2004.

Recebido para publicação em 12 de abril de 2005 Aceito para publicação em 10 de outubro de 2006 